\title{
Cidadania como Consumo ou Cidadania como Agência: uma comparação entre as reformas de democratização da Bolívia e do Brasil
}

PHILIP OKHORN:

\section{Resumo}

A primeira parte do artigo examina dois modelos opostos de cidadania, no contexto da América Latina: a cidadania como consumo, que reflete as consequências da influência de reformas orientadas para o mercado sobre os padrões de representação, no âmbito dos direitos políticos universais; e a cidadania como agência, que reflete o surgimento de formas alternativas de participação através da sociedade civil, bem como o seu potencial impacto sobre os padrões de representação política. A segunda parte discute o potencial da cidadania como agência, contrastando o impacto da Lei de Participação Popular da Bolívia com o Orçamento Participativo de Porto Alegre, no Brasil.

Palavras-chave: Cidadania. Agência. Sociedade civil. Lei de Participação Popular. Orçamento Participativo. Participação.

\footnotetext{
* Professor Associado do Departamento de Ciência Política da McGill University - Montreal Canadá. Diretor do Centre for Developing - Area Studies e Editor Executivo do Latin American Research Review.
} 


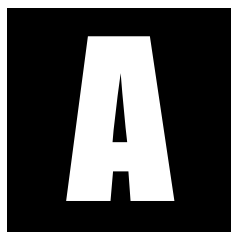

América Latina é, hoje, mais democrática do que em qualquer outro momento de sua história. Mas como são essas democracias que estão se tornando arraigadas ou consolidadas por toda a região? Mesmo que os governantes sejam eleitos através de eleições livres e justas, problemas graves como insegurança econômica individual, altos índices de criminalidade e uma crescente crise de representação, entre outros, contribuem para que as instituições democráticas sejam vistas, cada vez mais, como irrelevantes, ou, até mesmo, como um obstáculo, para lidar com os desafios que os latino-americanos enfrentam todos os dias (OXHORN, 2008). E são essas percepções que levam os líderes a contornar as instituições democráticas em um esforço para "fazer o trabalho". Essa ladeira escorregadia para um autoritarismo cada vez maior é, em última análise, a maior ameaça à democracia na América Latina.

Mas se a América Latina vai ou não seguir por essa ladeira escorregadia, isso depende do modelo de cidadania a ser adotado por essas democracias. Para ser mais específico, neste trabalho afirma-se que as democracias latino-americanas são caracterizadas por dois modelos opostos: cidadania como consumo e cidadania como agência. Depois de discutir como esses modelos refletem a qualidade do governo democrático, o artigo compara duas experiências recentes de reformas democráticas: a Ley de Participación Popular (Lei de Participação Popular) da Bolívia e o Orçamento Participativo do Brasil. A conclusão apresenta algumas generalizações para promover a cidadania como agência e reduzir os efeitos deletérios da cidadania como consumo.

\section{A Sociedade Civil e a Construção Social da Cidadania}

O ponto de partida para a análise que se segue é o conceito de sociedade civil, definido como: 
O tecido social formado por uma variedade de unidades auto-constituídas territorial e funcionalmente que coexistem pacificamente e coletivamente resistem à subordinação ao Estado, ao mesmo tempo em que exigem inclusão em estruturas políticas nacionais. (OXHORN, 1995)

Essa definição muda o foco do conteúdo normativo ou cultural da sociedade civil, para uma ênfase nas relações de poder em uma determinada sociedade. Uma sociedade civil forte reflete uma relativa dispersão do poder político nas formas de governo. O que, por sua vez, "contribui para o advento de regimes democráticos estáveis apoiados por sociedades civis fortes e vibrantes, cujos elementos componentes lutaram pela democracia em primeiro lugar" (OXHORN, 1995). Em sociedades onde o poder político está mais concentrado, a sociedade civil é fraca e as perspectivas de estabilidade democrática a longo prazo são, consequentemente, menores. O foco nas unidades auto-constituídas como partes componentes da sociedade civil destaca a importância da organização na construção do poder político. Mais especificamente, a capacidade de grupos subalternos para se organizarem de forma autônoma é uma das principais características na definição de uma sociedade civil forte, capaz de apoiar regimes democráticos estáveis.

Também é importante salientar que a dupla dinâmica "inclusão política" e "resistência à subordinação" sugere, paradoxalmente, que a sociedade civil não pode ser completamente compreendida fora da sua relação com o Estado. A autonomia da sociedade civil para com o Estado deve ser enfatizada, mas essa autonomia não implica isolamento. Pelo contrário, refere-se à capacidade das unidades sociais para definirem os seus interesses coletivos e agirem em busca dos mesmos, competindo uns com os outros.

Ao apresentar uma dicotomia entre "Estado" e "sociedade civil," grande parte da literatura a respeito da sociedade civil ignora o fato de que o Estado e a mesma, muitas vezes precisam trabalhar juntos para 
alcançar uma série de resultados importantes que, de outra forma, seriam inatingíveis. Esse relacionamento, mais fluido entre o Estado e a sociedade civil pode ser chamado de sinergia (cf. EVANS, 1997). A sinergia entre Estado e sociedade civil tem duas dimensões principais. A primeira é o que se poderia chamar de dimensão negativa ou prescritiva. Nesse nível, a sociedade civil desempenha um papel essencial, ao promover o respeito pelos direitos existentes, trabalhando para garantir que políticos e funcionários públicos continuem sendo responsáveis por seus atos (SMULOVITZ; PERUZOTTI, 2000). Igualmente importante é a segunda dimensão, que é positiva ou proibitiva. Esta inclui a definição de agendas públicas, incluindo a demanda por novas leis e novos direitos, e o trabalho junto ao Estado na concepção e implementação de políticas.

Para se obter uma sinergia efetiva entre Estado e sociedade civil, as instituições estatais devem estar abertas ao intercâmbio com a sociedade civil, com múltiplas arenas institucionais para facilitar a interação nos dois sentidos. Em um segundo paradoxo, o Estado frequentemente desempenha um papel central no fortalecimento da sociedade civil, através da concessão de incentivos e recursos para estimular a sua organização (SKOCPOL, 1996). O que é muito importante em uma região como a América Latina, onde a sociedade civil se tem mantido historicamente fraca, muitas vezes porque as políticas do Estado foram intencionalmente concebidas para reprimir o surgimento da mesma (OXHORN, 2006).

Mais genericamente, a natureza das relações entre o Estado e a sociedade civil se reflete em um processo aqui referido como a construção social da cidadania. De acordo com Tilly (1996), historicamente foi a "luta e negociação entre os estados em expansão e os seus subordinados [que] criou uma cidadania onde antes não existia." Mesmo hoje, quando há um consenso, talvez maior do que nunca, quanto ao conteúdo normativo dos direitos de cidadania democrática, ainda não há consenso no que diz 
respeito à implementação de muitos direitos específicos de cidadania. $\mathrm{Na}$ maior parte das novas democracias da América Latina, os conflitos acerca dos direitos básicos de cidadania estavam presentes na base do processo de transição, mas ainda não foram resolvidos. A incapacidade das instituições democráticas para enfrentar essas deficiências, mesmo depois da transição, é muitas vezes a melhor explicação para a sua fragilidade. As pressões pela expansão dos direitos de cidadania que surgem (ou deixam de surgir) na sociedade civil e a forma como o Estado lida com essas pressões, são elementos fundamentais para qualquer teoria causal da cidadania. Em outras palavras, a cidadania é o reflexo dos grupos que participam da sua construção social e da forma como participam. Assim sendo, a força da sociedade civil se reflete no âmbito e na profundidade dos direitos de cidadania.

O processo de interação entre Estado e sociedade civil leva a diferentes modelos de cidadania. O modelo predominante na América Latina costumava ser o da cidadania como cooptação. Esse modelo estava intimamente associado à industrialização e urbanização, a partir do início do Século XX, de vários países.

A pedra angular da cidadania como cooptação foi um processo único de inclusão controlada (OXHORN, 2003). A inclusão controlada consistia em processos verticais de inclusão política e social, nos quais os direitos de cidadania eram segmentados, parciais e, em última análise, precários. Ao invés de promover uma transformação significativa das estruturas de desigualdade, o processo refletia e reforçava as mesmas. Foi um projeto do Estado para mediar a ameaça representada pelas classes subalternas organizadas, através da sua incorporação seletiva e parcial, restringindo significativamente o alcance e a autonomia da sociedade civil, com políticas de corporativismo estatal, clientelismo e apelos populistas que se tornaram possíveis, graças aos recursos colocados à disposição das elites políticas como um subproduto do rápido crescimento econômico. 
Em suma, a inclusão controlada serviu para desmentir a existência de sociedades civis fortes; somente alguns segmentos da sociedade foram autorizados a se organizarem, e a autonomia dessas organizações foi seriamente comprometida. Importantes direitos sociais de cidadania foram concedidos em troca de direitos políticos também importantes, ao passo que a natureza autoritária do regime, por definição, impunha respeito pelos direitos civis básicos.

O modelo de cidadania como cooptação começou a ruir nas décadas de 1970 e 1980, como resultado dos limites do modelo de desenvolvimento da região e da crise da dívida, no início da década de 1980. Resultado também da coexistência da cidadania como cooptação com um modelo de cidadania concorrente, o da cidadania como agência. Esta última reflete o papel ativo que os múltiplos atores sociais, especialmente aqueles que representam os grupos desfavorecidos, devem desempenhar na construção social da cidadania para que o governo democrático alcance o seu potencial de incorporação. A cidadania como agência é sinônimo de sociedade civil forte na Europa Ocidental, onde um estado avançado de bem-estar social pode ser visto como uma das maiores conquistas desse modelo de cidadania.

Considerando-se o histórico latino-americano de extrema desigualdade e exclusão, o ideal da cidadania como agência, como era de se esperar, foi defendido pela esquerda. A democracia política era percebida, na melhor das hipóteses, como um instrumento a ser usado ou, na pior, uma armadilha burguesa. Ideologias da Guerra Fria poderiam ser usadas como uma desculpa da elite para inverter a inclusão controlada, impedindo, assim, que as estruturas fossem usurpadas em decorrência da expansão dos direitos de cidadania dos grupos desfavorecidos. Quando o modelo da cidadania como agência ameaçou tornar-se predominante, o resultado, na maioria das vezes, foi o golpe militar. 
Finalmente, é importante ressaltar que tanto a cidadania como cooptação quanto a cidadania como agência, durante a década de 1970, funcionaram como um reflexo da relação antagônica entre o Estado e a sociedade civil. O verdadeiro objetivo da inclusão controlada, que parecia oferecer a perspectiva de algum nível de cooperação entre o Estado e a sociedade civil, era a subordinação da sociedade civil ao Estado e aos interesses da classe dominante. A alternativa da cidadania como agência pretendia tomar o Estado para poder impor uma transformação social radical. De qualquer forma, o Estado e a sociedade civil estavam em posições diametralmente opostas, e cada um via no outro um inimigo a ser derrotado na luta pelos seus próprios interesses inconciliáveis.

Hoje, a dicotomia cidadania como agência / cidadania como cooptação perdeu a sua posição de destaque para um novo modelo de cidadania: a cidadania como consumo. Os cidadãos são mais bem compreendidos como consumidores, gastando seus votos e seus escassos recursos econômicos para ter acesso ao que deveriam ser direitos mínimos de cidadania democrática. Isso demonstra como as transições para a democracia na América Latina, desde meados da década de 1970, representam uma nova alternativa para a construção social da cidadania: o surgimento de direitos políticos universais na ausência de direitos civis universais e declínio dos direitos sociais. É um padrão de relações entre Estado e sociedade, que acentua os problemas históricos de desigualdade e de sociedades civis fracas, ao invés de solucioná-los.

A cidadania, como consumo, está intimamente relacionada a um modelo de incorporação política e integração social, voltado para o mercado, o neopluralismo. Os critérios políticos para a inclusão, em conjunto com a inclusão controlada (controle social e lealdade), são substituídos por critérios econômicos. Embora esteja associado a políticas econômicas neoliberais, o neopluralismo não pode ser reduzido a um conjunto espe- 
cífico de políticas econômicas ou correlacionado com qualquer nível de liberalização econômica.

O aspecto pluralista do neopluralismo indica uma crença normativa de que o melhor equilíbrio de interesses e valores, no contexto de um determinado regime, é o resultado de alguma forma (ainda que limitada) de livre concorrência entre os indivíduos envolvidos na busca racional de seus próprios interesses. A maior autoridade política é decidida em um livre mercado de votos. A liberdade individual é valorizada acima de tudo, o que implica em respeito pela propriedade privada e (seria o ideal) pelo Estado de Direito.

O que distingue o neopluralismo do modelo pluralista mais tradicional, associado com a democracia nos Estados Unidos, é o seu autoritarismo. Embora seja importante eleger os governantes, depois de eleitos, há pouco controle sobre o seu poder. Eles frequentemente driblam e sabotam deliberadamente as instituições democráticas representativas (O'DONNELL, 1994; OXHORN; DUCATENZEILER, 1998). Além disso, os detentores não-eleitos do poder, em particular os militares e os "poderes de fato," incluindo os interesses econômicos dominantes, exercem controle sobre as decisões estratégicas do Estado (GARRETÓN, 2003).

A lógica do neopluralismo permeia sistemas políticos inteiros em uma variedade de formas. Incentivos mercadológicos desempenham um papel decisivo na ação coletiva. Os recursos econômicos pessoais de um indivíduo determinam, em grande parte, o grau e a natureza de sua inclusão política e social. Os mesmos recursos afetam também a qualidade da educação, da saúde e até mesmo da proteção legal oferecida a este indivíduo (OXHORN, 2006). Assim como ao Estado é atribuído um papel mínimo na manutenção do bom funcionamento do mercado na esfera econômica, este abdica de seu papel como provedor de incentivos. Os bens públicos e privados disponíveis em nível estatal para aqueles 
que foram mobilizados em períodos anteriores, bem como os incentivos coercitivos da organização hierárquica de interesses econômicos sob o corporativismo estatal, deixaram de existir ou foram significativamente reduzidos. Identidades de grupo e interesses coletivos perdem qualquer valor intrínseco, mas constituem uma fonte de poder em potencial para grupos subalternos. A sinergia entre Estado e sociedade civil torna-se inviável, uma vez que o Estado mostra-se relutante e incapaz de trabalhar com a sociedade civil, e também porque o neopluralismo privilegia os recursos econômicos que faltam aos grupos menos favorecidos.

\section{Confrontando os limites da cidadania como consumo: reformas do Estado Participativo na Bolívia e no Brasil}

Os limites da cidadania como consumo refletem o fato de que a mesma é simultaneamente uma causa e um efeito das sociedades civis fracas. Os líderes políticos, em várias ocasiões, tentaram resolver este problema através de reformas de Estado inovadoras, com o objetivo de reforçar a sociedade civil, estabelecendo mecanismos para uma maior sinergia entre Estado e sociedade civil. Dois exemplos importantes de reformas são: a Lei de Participação Popular (LPP) da Bolívia e a experiência de Porto Alegre com o Orçamento Participativo (OP), no Brasil. Enquanto este último foi um sucesso em termos de criação de um modelo de cidadania como agência, a experiência boliviana tem sido muito mais problemática. A comparação entre os dois oferece insights importantes para se entender a sociedade civil e a cidadania na América Latina.

Lei de Participação Popular da Bolívia

Em muitos aspectos, a LPP representa uma tentativa deliberada de reforçar a sociedade civil, através da criação de mecanismos institucionais 
para alcançar a sinergia entre Estado e sociedade civil, e a cidadania como agência. Através de uma descentralização radical do Estado boliviano, em 1994, o cenário político da Bolívia foi completamente reorganizado em torno de 311 prefeituras; na maior parte, prefeituras novas erigidas precisamente onde o Estado antes se fazia o mais ausente ${ }^{1}$. Os governos municipais agora seriam responsáveis pela administração da saúde, da educação e dos serviços de infra-estrutura, entre outras áreas de investimento social. Sob um novo regime de partilha de receitas, o da co-participação, o Estado teria o dobro da porcentagem das suas receitas, que seriam compartilhadas com os governos municipais em $20 \%$. O resultado foi um bônus para os governantes das novas cidades, e das antigas também. Para $42 \%$ dos bolivianos que vivem em áreas rurais, a maioria deles, membros de comunidades indígenas, o Estado finalmente "chegou" - e com uma quantia de dinheiro sem precedentes, para ser gasto no local.

Cada município seria administrado por um Conselho Municipal eleito e um Prefeito. Para garantir que os novos recursos realmente beneficiariam a comunidade, mais de 16.000 Organizaciones Territoriales de Base - OTB (Organizações Territoriais de Base) foram legalmente reconhecidas em meados de 1997 (GALINDO SOZA, 1998). As OTBs foram consideradas os autênticos representantes dos interesses da sociedade civil da Bolívia, sendo que muitas delas eram organizações tradicionais, através das quais as comunidades indígenas se autogovernavam. Caberia às OTBs estabelecer as prioridades da comunidade, através de exercícios locais de planejamento participativo, em conjunto com a elaboração de um Programa Operativo Anual (POA) em cada município. As OTBs também selecionariam membros para uma nova instituição que representaria os interesses da comunidade junto à administração da cidade: os Comités de Vigilancia - CV (Comitês de Vigilância). Os comitês articulariam e re-

1 Dos 311 municípios reconhecidos pela LPP, 187 eram novos. 
presentariam as prioridades da comunidade nos processos do POA. Poderiam também supervisionar a parcela dos orçamentos municipais que foi financiada através da co-participação.

A LPP pretendia assegurar a responsabilização e a transparência governamental através da criação de uma forma híbrida de democracia, incorporando as tradições ocidentais da democracia representativa e as tradições indígenas das comunidades autônomas locais - "liberdade individual com simbiose comunitária" (Secretaría Nacional de Participación Popular, 1997). De uma só vez, a LPP ofereceu soluções institucionais para se enfrentarem muitos dos problemas que assolam a Bolívia, de um Estado fraco até o desenvolvimento de uma sociedade multiétnica. Embora tenha apresentado alguns casos de sucesso localizado, a LPP não correspondeu às expectativas no que diz respeito a uma maior sinergia entre Estado e sociedade civil ou à cidadania como agência. Muitos fatores ajudam a explicar esse fracasso.

Primeiro, a Lei de Participação Popular foi concebida e criada sem qualquer envolvimento da sociedade civil (GRINDLE, 2000). O então presidente Gonzalo Sánchez de Lozado participou ativamente, em estreita colaboração com seus principais assessores. Mas Víctor Hugo Cárdenas, um dos mais proeminentes líderes políticos de origem indígena da América Latina e vice-presidente da Bolívia na época, quase não tomou parte.

Em segundo lugar, a decisão de limitar a participação na LPP às OTBs fez com que as organizações funcionais ou corporativas fossem deliberadamente excluídas. Ironicamente, com essa decisão, foram excluídos os comitês cívicos, aqueles que seriam os principais agentes da sociedade civil boliviana na defesa da descentralização. Os demais setores da sociedade mantiveram-se relativamente quietos sobre o assunto. Os comitês cívicos se haviam tornado uma alternativa cada vez mais importante ao corrupto sistema político-partidário da Bolívia, mas a maior parte deles 
era de origem urbana, e eles muitas vezes mantinham laços estreitos com grupos empresariais, o que gerou desconfiança entre os arquitetos da LPP. A proibição imposta pela LPP aos financiamentos municipais para comitês cívicos empurrou-os para a crise financeira (Programa das Nações Unidas para o Desenvolvimento - PNUD, 1998).

Tendo afastado do quadro da LPP os principais grupos de defesa da descentralização, o sucesso da mesma passou a depender de setores da sociedade civil que não haviam participado da sua elaboração, e que historicamente nunca confiaram no Estado boliviano. Com pouco ou nenhum apoio social para a LPP, o Governo precisava conquistar a opinião pública, uma vez que a lei já estava em vigor e havia uma campanha de oposição bastante eficaz contra as "leyes malditas", a qual foi capaz de mobilizar apoio significativo de diversas fontes, incluindo partidos políticos, organizações funcionais (especialmente o trabalho organizado) e organizações não-governamentais. A repressão aos manifestantes nublou ainda mais a legitimidade da LPP durante a sua implementação (VAN COTT, 2000).

A chave para a solução desse problema, no final, foi a disponibilidade dos fundos de co-participação. Conforme mencionado por Carlos Hugo Molina, autor intelectual da LPP e primeiro Secretário Nacional de Participación Popular, "a peça chave para a consolidação da participação popular foi a existência de recursos. As pessoas associavam a participação popular com os recursos" (entrevista pessoal, Santa Cruz, 15 de julho de 1999). Em quatro meses, a contar da promulgação da lei, foram disponibilizados mais recursos do que a soma dos últimos três anos e em muitos casos, principalmente nas zonas rurais, aquela era a primeira vez em que recebiam recursos do Estado. De fato, de acordo com Molina, um aspecto central da campanha do governo para encorajar o apoio às novas instituições foi a divulgação da quantia de dinheiro que chegava aos governos locais para que as pessoas tivessem um incentivo para exercer alguma 
forma de controle sobre as despesas desses governos. Como era de se esperar, uma das razões por trás da rápida legalização de tantas OTBs foi o desejo de ter acesso a esses recursos, o que, em muitos casos, reflete o empenho dos partidos políticos em obter reconhecimento para as OTBs com as quais estavam envolvidos, para que também pudessem ter acesso aos recursos (BOOTH et al., 1997).

Além da óbvia contradição de criar instituições estatais participativas sem o envolvimento do público na sua concepção, outra contradição, ainda maior, está relacionada aos modelos de cidadania: para legitimar as reformas institucionais que representam a cidadania como agência, o Estado recorreu a um modelo de cidadania como cooptação. Esta ambiguidade na motivação para as reformas só serviu para aumentar a desconfiança dos grupos pobres, marginalizados, que já estavam apreensivos quanto ao esforço do Estado para adequar os interesses políticos ao bem público.

A decisão de limitar a participação na LPP às organizações territoriais também levantou sérias questões quanto à representação dos grupos marginais e à sua manipulação por parte das elites políticas. Índices demográficos e de migração de zonas rurais decadentes revelaram que muitas OTBs estavam estagnadas, organizações moribundas que haviam perdido seu apelo junto aos habitantes locais (BOOTH et al., 1997). O súbito afluxo de recursos do Governo Central deu nova vida às OTBS, mas elas foram logo dominadas por elites políticas locais e representantes de partidos políticos. Em outros casos, as organizações foram formadas com o intuito de canalizar esses fundos, sem que houvesse qualquer conexão real com a sociedade. Essas organizações eram caracterizadas como "impostas, artificiais" (entrevista pessoal, Ana María Lema, Santa Cruz, 15 de julho de 1999). Problemas como esses são particularmente graves em zonas urbanas, onde as juntas vecinales (associações comunitárias) são a principal forma de OTB. Um estudo do PNUD (1998) constatou que menos de 30\% dos moradores 
participavam dessas associações e que a maior parte deles era de homens com mais de 30 anos, de classes sócio-econômicas privilegiadas. Também foi constatada a influência de partidos políticos (Programa das Nações Unidas para o Desenvolvimento - PNUD, 1998).

Em termos mais gerais, houve pouco esforço para mobilizar a participação do cidadão, para fazer com que as pessoas realmente se envolvessem com a política local (BOOTH et al., 1997), principalmente entre os jovens. Um levantamento nacional realizado pelo PNUD (1998) constatou que $73,7 \%$ das pessoas entre 21 e 30 anos de idade não tinham contato com as organizações locais, especialmente as mulheres².

Em contraste, as organizações mais dinâmicas foram aquelas funcionais, mais especificamente os comitês que se formaram para garantir irrigação e água potável. A explicação para o dinamismo desses comitês está no fato de terem algo de concreto para oferecer aos seus membros. Os comitês bem-sucedidos não se dispersaram depois de obter a irrigação ou a água potável e mostraram capacidade para entrar em outras áreas de atividade relacionadas com o desenvolvimento da comunidade.

O problema era ainda mais acentuado no caso da representação feminina, apesar do compromisso formal da LPP de proporcionar igualdade de oportunidades entre homens e mulheres. A representação feminina nos governos municipais diminuiu não apenas relativamente, mas também absolutamente, não obstante o fato de a LPP ter mais do que dobrado o número de governos municipais na Bolívia. A situação era tão séria que os reformistas instituíram uma cota de 30\% de candidatas do sexo feminino. Embora isso pareça uma conquista significativa para as mulheres, muito do impacto da cota foi diluído pelo fato de que as mulheres foram relegadas à posição de "suplentes", onde elas representam 70\%, esperan-

2 Isso mudou drasticamente durante os protestos que abalaram a Bolívia e encerraram o segundo mandato presidencial de Sánchez Lozado, em 2003, evidenciando a incapacidade da Lei de Participação Popular para criar novos mecanismos de inclusão. 
do para substituir conselheiros municipais em caso de demissão ou transferência para o gabinete do prefeito (KUDELKA, 2004). Isso mostra como os homens tentaram controlar o acesso aos novos recursos proporcionados pela co-participação, empurrando as mulheres (às vezes com violência) para fora da disputa (KUDELKA, 2004). Essa situação resulta também da exclusão das organizações femininas da participação no processo da LPP, porque elas não foram consideradas OTBs. Os homens têm dominado as OTBs, desde antes de elas terem acesso a recursos públicos tão substanciais (BOOTH et al., 1997; VARGAS R., 1998). Uma pesquisa de 1999 sobre as taxas de participação feminina nas OTBs constatou que são 24 homens participantes para cada mulher que participa, embora fosse esperada uma melhora depois da lei de cotas de 1997 (KUDELKA, 2004).

Esses problemas foram agravados pela forma como o orçamento participativo e os comitês de vigilância funcionam na prática. Em termos de planejamento participativo, a "participação" através das OTBs geralmente está limitada a definir prioridades para os gastos e a fazer exigências, ao invés de realmente participar do processo de planejamento (ARCHONDO 1997; VARGAS R., 1998; BOOTH et al., 1997). Isso se deve, em parte, ao fato de que o processo de planejamento não foi projetado para um envolvimento mais ativo da sociedade civil. Mas reflete também os antigos padrões de uma relação mais paternalista (e às vezes conflituosa) entre o Estado e a sociedade civil, onde a sociedade civil buscava no Estado a solução dos seus problemas.

O problema da participação limitada é acentuado pela falta de sincronia entre as prioridades estabelecidas pelo orçamento participativo e a realidade dos orçamentos municipais. Em 2000, apenas 23\% dos projetos financiados pelos governos municipais vieram dos processos do orçamento participativo ${ }^{3}$. Mas não basta estar incluído no orçamento municipal,

3 Uma reforma subsequente aumentou esse índice para 45\%. (ver GALINDO SOZA, 2004). 
porque nem sempre os programas orçamentados são implementados. Um estudo realizado por Porcel e Thévoz em 1998, com 151 governos municipais, constatou que pouco mais do que $50 \%$ dos orçamentos foram realmente executados.

Se as organizações territoriais são o alicerce sobre o qual repousa a LPP, os comitês de vigilância são os pilares centrais. A criação de 311 comitês de vigilância foi um processo lento. Em dezembro de 1995 havia somente $163 \mathrm{CVs}$, o que fez com que o governo estipulasse um prazo até 31 de dezembro daquele mesmo ano para a formação de comitês elegíveis para os fundos de co-participação. "Em 15 dias, todos os partidos políticos que governavam municípios criaram comitês de vigilância" (ARDAYA SALINAS, 1998). Além de levantar questões sobre a representatividade dos CVs (ARDAYA SALINAS, 1998), essa situação revela a falta de reconhecimento social quanto ao papel que os comitês podem desempenhar no fortalecimento da sociedade civil. Institucionalmente, eles foram criados pelo Estado e não têm legitimidade social. O resultado é uma relação formal entre os comitês e as comunidades que eles deveriam representar: "a base faz exigências, mas não apóia" os CVs (MAYDANA, 2004).

Como era de se esperar, os comitês raramente cumprem o seu papel de supervisão (MAYDANA, 2004; GUZMÁN BOUTIER 1998; BOOTH et al., 1997). Em um estudo com 11 CVs, somente dois deles estavam em funcionamento, com limitações significativas em ambos os casos. A tarefa se torna ainda mais difícil por causa da confusão quanto ao verdadeiro papel dos CVs, especialmente no que diz respeito ao exercício do controle social sobre as despesas dos fundos de co-participação. Além disso, os CVs dependem de informações vitais fornecidas pelo governo municipal, e este, muitas vezes, simplesmente se recusa a fornecê-las. Isso pode criar um círculo vicioso de desconfiança e conflito entre os governos municipais e as organizações credenciadas pela LPP. 
Há outros problemas sérios, relacionados à autonomia dos comitês. Uma variedade de fatores contribui para afastar os CVs de suas bases sociais. As grandes distâncias, em muitas jurisdições rurais, fazem com que os membros do CV, em especial o presidente, se afastem de suas comunidades por longos períodos de tempo. Grande parte do trabalho dos CVs, portanto, tem lugar "onde a pressão moral é mais fraca, o custo de vida é alto, e as tentações políticas não são irrelevantes" (BOOTH et al., 1997).

Mesmo que sejam autônomos com relação à sua base social, os comitês são vulneráveis à manipulação por parte dos governos locais e dos partidos políticos. A LPP, deliberadamente, não financia as atividades dos CVs, em uma tentativa equivocada de impedir que se tornem uma fonte de patronagem ${ }^{4}$. Além disso, a tarefa de supervisor fiscal é muito técnica, e poucos membros de CV têm as habilidades necessárias para desempenhar essa tarefa. Isso aumenta ainda mais a vulnerabilidade dos membros de comitês às pressões políticas do município (BOOTH et al., 1997). Consequentemente, os membros de CVs, principalmente os presidentes, que muitas vezes exercem forte influência sobre os seus respectivos comitês, estão cada vez mais expostos à dinâmica patrimonial e rentista da política boliviana (Programa das Nações Unidas para o Desenvolvimento - PNUD, 1998; MAYDANA, 2004).

Longe de criar sinergia entre Estado e sociedade civil, ou um modelo de cidadania como agência, a LPP foi vítima de muitos dos piores aspectos do antigo modelo de cidadania como cooptação. Em uma atmosfera social caracterizada por altos níveis de desconfiança e ceticismo em relação ao Estado, a existência continuada da LPP contradiz uma sociedade civil forte.

4 Em 1999, foram criados os Fundos de Controle Social para financiar as atividades dos Comitês de Vigilância. Mas não foi o suficiente, e não havia mecanismos para garantir que o dinheiro fosse gasto de forma apropriada. Com algumas exceções, a experiência só serviu para levantar dúvidas sobre a legitimidade social dos CVs, e não reduziu a sua vulnerabilidade à manipulação política (ver MAYDANA, 2004). 
Na verdade, como se pode constatar pela instabilidade política da Bolívia nos últimos anos, o controle e a participação social cada vez mais seguem a lógica da "sociedade civil contra o Estado" (MAYDANA, 2004).

\section{Orçamento Participativo de Porto Alegre}

O Orçamento Participativo (OP) teve início em 1989, em Porto Alegre, uma cidade de médio porte (população de 1,2 milhões) no sul do Brasil. Embora fosse muito menos ambicioso do que a Lei de Participação Popular da Bolívia, o OP também procurou criar novas instituições para implementar a sinergia entre Estado e sociedade civil e a cidadania como agência a nível local, mas com muito mais sucesso. De fato, seu sucesso estrondoso levou à adoção de programas semelhantes em mais de 100 cidades no Brasil, bem como em muitos outros em todo o mundo. Na comparação entre o relativo sucesso do OP com a LPP, surgem dinâmicas importantes que ajudam a explicar por que a cidadania como agência muitas vezes é tão problemática ${ }^{5}$.

O impulso para o OP veio da esfera nacional. Em nítido contraste com o processo isolado e sigiloso através do qual a LPP foi projetada, o OP no Brasil foi possibilitado pela Constituição de 1988, que foi elaborada com uma participação significativa da sociedade civil. A nova Constituição tornou possível o OP ao conceder autoridade aos governos locais para criar novos processos de formulação de políticas e reconhecer a legitimidade das instituições participativas (WAMPLER; AVRITZER, 2004). Ao invés de impor um projeto institucional único para todo o país, a Constituição brasileira de 1988 facilitou a experimentação local e Porto Alegre aceitou o desafio.

5 Mesmo que os desafios impostos ao OP em Porto Alegre não fossem tão preocupantes quanto aqueles impostos à LPP, é importante ressaltar que a LPP falhou a nível local, devido à capacidade do governo central para comandar mudanças radicais. As mesmas dinâmicas da esfera nacional (corrupção, influência partidária excessiva e clientelismo generalizado) também foram uma ameaça potencial ao sucesso do OP em Porto Alegre. 
Diversos fatores locais exerceram influência sobre a direção das novas reformas em Porto Alegre. A cidade havia desfrutado de uma sociedade civil particularmente vibrante, que cresceu em oposição à ditadura militar brasileira (1964-1985). Mas essa experiência foi ofuscada em 1986, com a vitória eleitoral do Partido Democrático Trabalhista (PDT), um partido populista de esquerda que desmobilizou a sociedade civil para reintroduzir um governo clientelista mais tradicional. A proposta inicial de alguma forma de orçamento participativo surgiu no seio da sociedade civil, para renovar a legitimidade das organizações da sociedade civil em face do clientelismo generalizado do governo do PDT (AVRITZER, 2002; BAIOCCHI, 2002; WAMPLER; AVRITZER, 2004).

O Partido dos Trabalhadores (PT), também de esquerda, venceu as eleições municipais de 1988, em grande parte por causa do repúdio do público ao PDT, uma vez que o PT ainda não se havia estabelecido como um partido forte em Porto Alegre. Apesar das divisões internas do PT (GOLDFRANK, 2003), o partido decidiu fazer do Orçamento Participativo a pedra angular da sua política municipal (BAIOCCHI, 2002; AVRITZER, 2002). Contribuiu para essa decisão a estreita relação entre o PT e os muitos atores da sociedade civil que lutavam por uma maior participação popular no Governo Municipal. De fato, essa relação entre compromisso partidário e ligações estreitas com movimentos sociais autônomos (ainda que simpatizantes) foi fundamental para o sucesso do OP (HELLER, 2001).

Apesar das circunstâncias favoráveis, o OP teve um começo difícil. A participação foi relativamente baixa e até diminuiu durante os primeiros dois anos (GOLDFRANK, 2003). A resposta do PT foi trabalhar com organizações da sociedade civil, negociar e aperfeiçoar as instituições do OP. Os níveis de financiamento aumentaram junto com o escopo do OP, de modo que, no fim da década de 1990, 100\% de todas as despesas discricionárias do município foram decididas através do OP (WAMPLER; 
AVRITZER, 2004). Também foram realizados esforços no sentido de encorajar os participantes locais a pensarem além de suas comunidades imediatas, e assim o OP começou a responder às preocupações da cidade como um todo (BAIOCCHI, 2002).

O Orçamento Participativo envolve um ciclo anual, que começa em março, com assembléias em cada um dos 16 distritos da cidade. Os delegados são então eleitos para representar suas comunidades locais nas próximas fases do ciclo. O Conselho do OP, com 42 membros, é eleito para negociar o orçamento final com o Governo Municipal. Orçamentos e projetos do ano anterior são revisitados. Depois disso, os delegados se encontram em reuniões intermediárias para determinar as prioridades regionais e discutir as preocupações mais gerais da cidade como um todo, de acordo com os grupos temáticos que foram designados. O Conselho do OP também é responsável pelo equilíbrio entre demandas concorrentes, pela definição de prioridades e pela distribuição de fundos entre as regiões e em conformidade com as prioridades da cidade. Depois de negociar o orçamento final do município, o Conselho do OP monitora as despesas reais (AVRITZER, 2002; BAIOCCHI, 2002).

O resultado final do OP representa "uma profunda transformação da própria sociedade civil" (BAIOCCHI, 2002). O nível de participação do público vem aumentando continuamente, de apenas 976 participantes em 1990 para 26.807 em 2000 (WAMPLER; AVRITZER, 2004). Em contraste com a LPP, a participação é aberta a todos. Ficou decidido que a participação não seria limitada àqueles já envolvidos com organizações da sociedade civil, e as pessoas frequentemente são convidadas a participar pela primeira vez. Além disso, o número de organizações sociais tem aumentado significativamente, como resultado do processo do OP. Estimativas conservadoras sugerem que o número de associações de bairro aumentou de 180 em 1986 para 540 em 1998 (BAIOCCHI, 2002). Enfim, o OP tornou- 
se um exemplo de como "organizações da sociedade civil desafiam velhas práticas, tais como o clientelismo e a patronagem, e, ao mesmo tempo, oferecem alternativas concretas" (WAMPLER; AVRITZER, 2004).

Os níveis crescentes de participação e organização tendem a se concentrar nas áreas mais pobres e as pessoas com baixa renda e menor grau de instrução são a maioria no processo do OP. Além disso, as despesas municipais foram deliberadamente redistribuídas entre as áreas mais pobres da cidade. Tudo isso serve para demonstrar o poder de decisão que o OP oferece aos grupos desfavorecidos. Mais especificamente, os cidadãos podem ver como as suas atividades coletivas contribuem de forma positiva para a elaboração de políticas públicas, criando um círculo virtuoso que fortalece a sociedade civil, redistribui o poder político e econômico e contribui para um governo mais inclusivo e democrático.

\section{Sociedade Civil, Estado e a busca pela Cidadania como Agência}

Os obstáculos para se colocar em prática a cidadania como agência, impostos pelo modelo dominante de cidadania como consumo e pelo neopluralismo, podem parecer intransponíveis. No entanto, a experiência do OP em Porto Alegre aponta o caminho para que se possa implementar a cidadania como agência na América Latina hoje. A vontade política, embora seja necessária, não é suficiente para alcançar a cidadania como agência. Este era o objetivo das pessoas que projetaram a Lei de Participação Popular, mas, afastadas da sociedade civil, as instituições que eles criaram não poderiam cumprir as suas promessas. Seus métodos excludentes tornaram quase impossível alcançar a concepção de democracia inclusiva que orientou seus esforços. Ao invés de criar processos cumulativos através dos quais a participação do cidadão e a organização 
autônoma da sociedade civil poderiam aumentar, ocorreu justamente o contrário. O ceticismo inicial em relação ao Estado se foi agravando, tanto pela forma como a LPP foi implementada, quanto pelos seus próprios limites, que mais refletiam as visões e (des)entendimentos da elite, do que as necessidades e aspirações dos cidadãos bolivianos.

Também é preciso reconhecer que a contradição no cerne da LPP foi fatal para o fortalecimento da sociedade civil e criação da cidadania como agência. Elementos importantes da cidadania como cooptação, na forma de receitas de co-participação, estavam lá para ofuscar as grandes pretensões da LPP, bem como a ausência de mecanismos eficazes para garantir que o bem público acabaria por prevalecer. Tudo isso contrasta com a experiência do OP em Porto Alegre. Trabalhando em conjunto com a sociedade civil, criou-se uma alternativa clara e poderosa para a cidadania como cooptação ou consumo, literalmente, de baixo para cima. $\mathrm{O}$ intercâmbio sinérgico entre o PT, como um partido político, a sociedade civil, e o Estado local deu origem a um processo que fortaleceu a sociedade civil e a qualidade da cidadania.

É importante não exagerar o sucesso do OP em Porto Alegre. Este é, com certeza, o exemplo de maior sucesso entre mais de 100 experiências similares, em um país com mais de 5.000 prefeituras. Mas, por mais importante que seja para os cidadãos de Porto Alegre, o OP só controla de 10 a 15\% das despesas municipais, o que representa uma renda per capita de apenas US\$200 (WAMPLER; AVRITZER, 2004). Embora se trate de um importante direito de cidadania, que torna possível decidir onde a escola vai ser construída, questões mais importantes, sobre a equipe e o currículo da escola, por exemplo, são decididas em outros lugares. $\mathrm{O}$ próximo desafio é expandir o OP para que possa definir políticas nacionais e / ou descentralizar o poder de decisão dos governos locais para que possam tratar de questões mais amplas. 
Ironicamente, este último era um dos objetivos da Lei de Participação Popular da Bolívia. Mas a óbvia contradição entre os métodos utilizados para alcançá-lo prejudicou a promessa da LPP. Resta saber se um processo mais consistente - um que trabalha em conjunto com a sociedade civil para construir sobre os seus pontos fortes preexistentes - se sairia melhor. Como a Bolívia luta pelo fim do seu atual período de extrema instabilidade política, é possível que o verdadeiro desafio da sua próxima geração de líderes políticos seja tentar descobrir.

\title{
Citizenship as Consumption or Citizenship as Agency: comparing democratizing reforms in Bolivia and Brazil
}

\begin{abstract}
The paper first discusses 2 opposing models of citizenship within Latin American: citizenship as consumption, which reflects the consequences of the pervasive influence of market-oriented reforms on patterns of representation in the context of universal political rights, and citizenship as agency, which would reflect the emergence of alternative forms of participation through civil society and their potential impact on political patterns of representation. The second part of the paper then examines the potential for citizenship as agency to emerge by contrasting the impact of the Popular Participation Law in Bolivia and Participatory Budgeting in Porto Alegre, Brazil.
\end{abstract}

Keywords: Citizenship. Agency. Civil Society. Popular Participation Law. Participatory Budgeting. Participation. 


\section{Referências}

ARCHONDO, Rafael. La aplicación de la Ley de Participación Popular. In: El pulso de la democracía. La Paz: Secretaría Nacional de Participatción Popular y Editorial Nueva Sociedad. Ed. Secretaría Nacional de Participación Popular, 1997. ARDAYA SALINAS, Rubén. El comité de vigilancia al auxilio de la democracia municipal. La Paz: Instituto Latinoamericano de Investigaciones Sociales de la Funación Friedrich Ebert Stiftung, 1998.

AVRITZER, Leonardo. Democracy and the Public Space in Latin America. Princeton: Princeton University Press, 2002.

BAIOCCHI, Gianpaolo. Synergizing Civil Society: State-Civil Society Regimes in Porto Alegre, Brazil. Political Power and Social Theory, n. 15, 2002, p. 3-52.

BOLIVIA. El pulso de la democracia. La Paz: Secretaría Nacional de Participación Popular y Editorial Nueva Sociedad, 1997.

BOOTH, David; CLISBY, Suzanne; WIDMARK, Charlotta. Popular Participation: Democratising the State in Rural Bolivia. Stockholm: Swedish Internaitonal Development Cooperation Agency, 1997.

BUSTAMANTE, Fernando. 1998. Democracy, Civilizational Change and the Latin American Military. In: Fault Lines of Democracy in Post-Transition Latin America. AGUERO, F; STARK, J. (Eds). Miami: North-South Center Press (University of Miami), 1998.

EVANS, Peter. Introduction: Development Strategies Across the Public-Private Divide. In: State-Society Synergy: Government and Social Capital in Development. EVANS, P. (Ed.). Berkeley: International Area Studies, University of California, Berkeley, 1997.

GALINDO SOZA, Mario. La participación popular y la descentralización administrativa. In: Las reformas estructurales en Bolivia. CORRALES, J. C. Chávez (Ed.). La Paz: Fundación Milenio, 1998.

. Diez Años de planificación participativa en el proceso de la participación popular. In: Municipalización: diagnóstico de una década. La Paz: USAID, Friedrich Ebert Stiftung, ILDIS, 2004.

GARRETÓN, Manuel Antonio. Incomplete Democracy: Political Democratization in Chile and Latin America. Chapel Hill: University of North Carolina, 2003.

GOLDFRANK, Benjamin. Making Participation Work in Porto Alegre. In: Radicals in Power: The Workers' Party (PT) and experiments in urban democracy in Brazil. BAIOCCHI, G. (Ed.). London: Zed Books Ltd, 2003. 
GRINDLE, Merilee S. Audacious Reforms: Institutional Invention and Democracy in Latin America. Baltimore: John Hopkins University Press, 2000.

GUZMÁN BOUTIER, Omar. Denuncias del comité de vilancia o cuándo efectivo es el control social. In: Participación Popular. Una evaluación-aprendizaje de la Ley 1994-1997. La Paz: Ministerio de Desarrollo Sostenible y Planificación, Viceministerio de Participación Popular y Fortalecimiento Municipal, 1998.

HELLER, Patrick. Moving the State: The Politics of Democratic Decentralization in Kerala, South Africa, and Porto Alegre. Politics \& Society, v. 29, n.1, 2001, p. 131-163.

KUDELKA, Ana María. Análisis de las políticas de género desde un enfoque gerencial y su impacto a nivel municipal. In: Municipalización: diagnóstico de una década. La Paz: USAID, Friedrich Ebert Stiftung, ILDIS, 2004.

MAYDANA, Raúl. El comité de vigilancia, la participación y el control social en el modelo municipalista de descentralización del Estado boliviano. In: Municipalización: diagnóstico de una década. La Paz: USAID, Friedrich Ebert Stiftung, ILDIS, 2004.

O'DONNELL, Guillermo. Delegative Democracy. Journal of Democracy, v. 5, n. 1, 1994, p.56-69.

OXHORN, Philip. From Controlled Inclusion to Coerced Marginalization: The Struggle for Civil Society in Latin America. In: Civil Society: Theory, History and Comparison. HALL, J. (Ed.). Cambridge: Polity Press, 1995.

. Social Inequality, Civil Society and the Limits of Citizenship in Latin America. In: What Justice? Whose Justice? Fighting for Fairness in Latin America. ECKSTEIN, S.; WICKHAM-CRAWLEY, T. Berkeley: University of California, 2003.

. Conceptualizing Civil Society from the Bottom Up: A Political Economy Perspective. In: Civil Society and Democracy in Latin America. FEINBERG, R.; W. C. H. ; ZAMOSC, L. (Eds.). New York: Palgrave Macmillan, 2006.

. Neopluralismo y los retos a la ciudadanía en Latinoamérica. In: Identidad, sociedad y política. LIWERANT, J. Bokser; CRUZ, S. Velasco (Eds.). Mexico, DF: UNAM, 2008.

OXHORN, Philip; DUCATENZEILER, Graciela. (eds.). What Kind of Market? What Kind of Democracy? Latin America in the Age of Neoliberalism. University Park: Pennsylvania State University Press, 1998.

PNUD (Programa de Las Naciones Unidas Para el Desarrollo). Desarrollo Humano en Bolivia 1998. La Paz: Programa de Las Naciones Unidas Para el Desarrollo, 1998. 
SKOCPOL, Theda. Unravelling from Above. American Prospect, n. 25, 1996.

SMULOVITZ, Catalina; PERUZOTTI, Enrique. Societal Accountability in Latin America. Journal of Democracy, v. 11, n. 4, 2000, p.147-158.

TILLY, Charles. Citizenship, Identity and Social History. In: Citizenship, Identity and Social History, International Review of Social History Supplement, v. 3. TILLY, C. (Ed.). Cambridge: Press Synidicate of the University of Cambridge, 1996.

VAN COTT, Donna. The Friendly Liquidation of the Past: The Politics of Diversity in Latin America. Pittsburgh: University of Pittsburgh Press, 2000.

VARGAS R., Humberto. Los municipios en Bolivia. Son evidentes los avances con participación popular. Cochabamba: Centro de Estudios de la Realidad Económica y Social, 1998.

WAMPLER, Brian; AVRITZER, Leonardo. Participatory Publics: Civil Society and New Institutions in Democratic Brazil. Comparative Politics, v. 36, n.3, 2004, p.291-312.

Recebido: $13 / 04 / 2010$

Aceite final: 19/04/2010 